\title{
An unusual case of jejunal choriocarcinoma detected by single-balloon endoscopy
}

A 41-year-old woman was admitted to our institution because of massive melena and symptomatic anemia ( $\mathrm{Hb} 5.3 \mathrm{~g} / \mathrm{dL}$ ). The patient had previously undergone a cesarean section and tubal ligation 3 years ago while giving birth to her second child. Neither esophagogastroduodenoscopy nor colonoscopy identified the source of bleeding. Single-balloon endoscopy revealed a lobulated purplish tumor over the proximal jejunum ( $\bullet$ Fig. 1 ). Due to the tendency to bleed, only a limited biopsy specimen was obtained, and a poorly differentiated carcinoma was impressed. A computed tomography (CT) scan revealed several hypodense lesions in both lobes of the liver $(1-2.5 \mathrm{~cm}$ in diameter), and a soft tissue mass over the right suprahilar region. No further lesion was detected by the systematic survey.

The patient underwent an emergency laparoscopy to control the continued heavy gastrointestinal bleeding. Laparoscopic reduction of jejunojejunal intussusception and segmental resection of the jejunum were performed ( $\bullet$ Fig. 2 ). The final histological diagnosis of the surgically resected specimen was choriocarcinoma of the jejunum ( Fig.3). The level of serum $\beta$ human chorionic gonadotropin ( $\beta-\mathrm{HCG}$ ) determined after pathological diagnosis was 241 991 IU/L.

Choriocarcinomas of the small intestine, including both primary and metastatic tumors, are rarely encountered $[1,2]$. They are seen most commonly in the jejunum, followed by the duodenum, and least commonly seen in the ileum [2]. The pure choriocarcinoma without other malignant elements identified by immunohistochemical analysis is not sufficient to exclude the possibility of primary choriocarcinoma of the jejunum [2,3]. In the present case, a gestational origin for the jejunal choriocarcinoma was confirmed by analyzing genetic polymorphisms in the tumor [4] ( Fig.4). The majority of gestational choriocarcinomas develop shortly after the preceding gestation [5]. In the absence of uterine tumors, the diagnosis of the late onset of gestational choriocarcinoma at an unusual metastatic site is a challenge to clinicians. This is the first report of jejunal choriocarcinoma detected by single-balloon endoscopy.

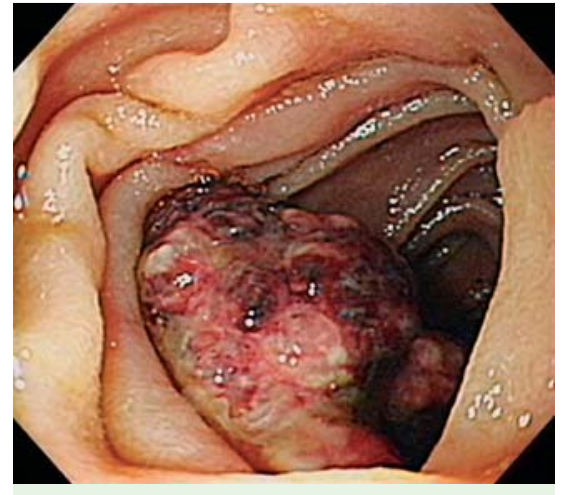

Fig. 1 Single-balloon enteroscopy showed a 3-cm lobulated vascular tumor over the proximal jejunum $25 \mathrm{~cm}$ distal to the Treitz ligament.

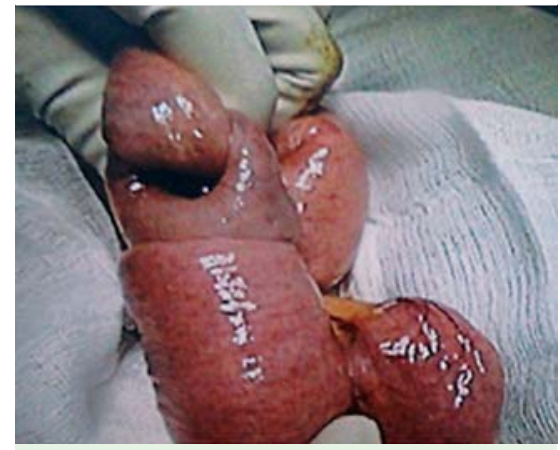

Fig.2 Intraoperative findings included a 4-cm tumor at the proximal jejunum with serosal invasion causing intussusception.

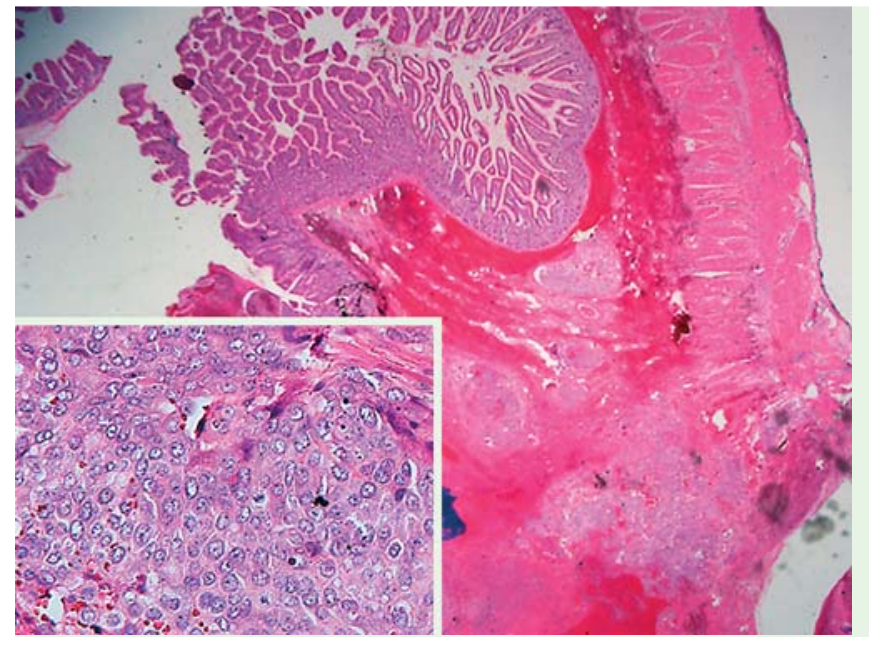

Fig. 3 Microscopic examination showed the tumor, consisting of two cell patterns, embedded in a hemorrhagic background with jejunal muscular and mucosal involvement. One group was composed of hyperchromatic pleomorphic tumor cells with vesicular nuclei and a medium amount of eosinophilic cytoplasm, the other was composed of multinuclear giant cells. (Hematoxylin and eosin stain.)

Endoscopy_UCTN_Code_CCL_1AD_2AB

Competing interests: None

\section{Y.-J. Tai ${ }^{1}$, T.-C. Lee ${ }^{2}$, L.-H. Tseng ${ }^{3}$, L.-H. Wei ${ }^{1}$}

${ }^{1}$ Department of Oncology, National Taiwan University Hospital and National Taiwan University College of Medicine, Taipei, Taiwan

${ }^{2}$ Department of Internal Medicine, National Taiwan University Hospital and National Taiwan University College of Medicine, Taipei, Taiwan

${ }^{3}$ Department of Medical Genetics, National Taiwan University Hospital and National Taiwan University College of Medicine, Taipei, Taiwan

\section{Acknowledgments \\ $\nabla$}

The pathology review was made by $\mathrm{Dr}$ Kuan-Ting Kuo, Department of Pathology, National Taiwan University Hospital. A thoughtful review of this article was made by Dr Ruey-Jien Chen, Department of Obstetrics and Gynecology, National Taiwan University Hospital. 

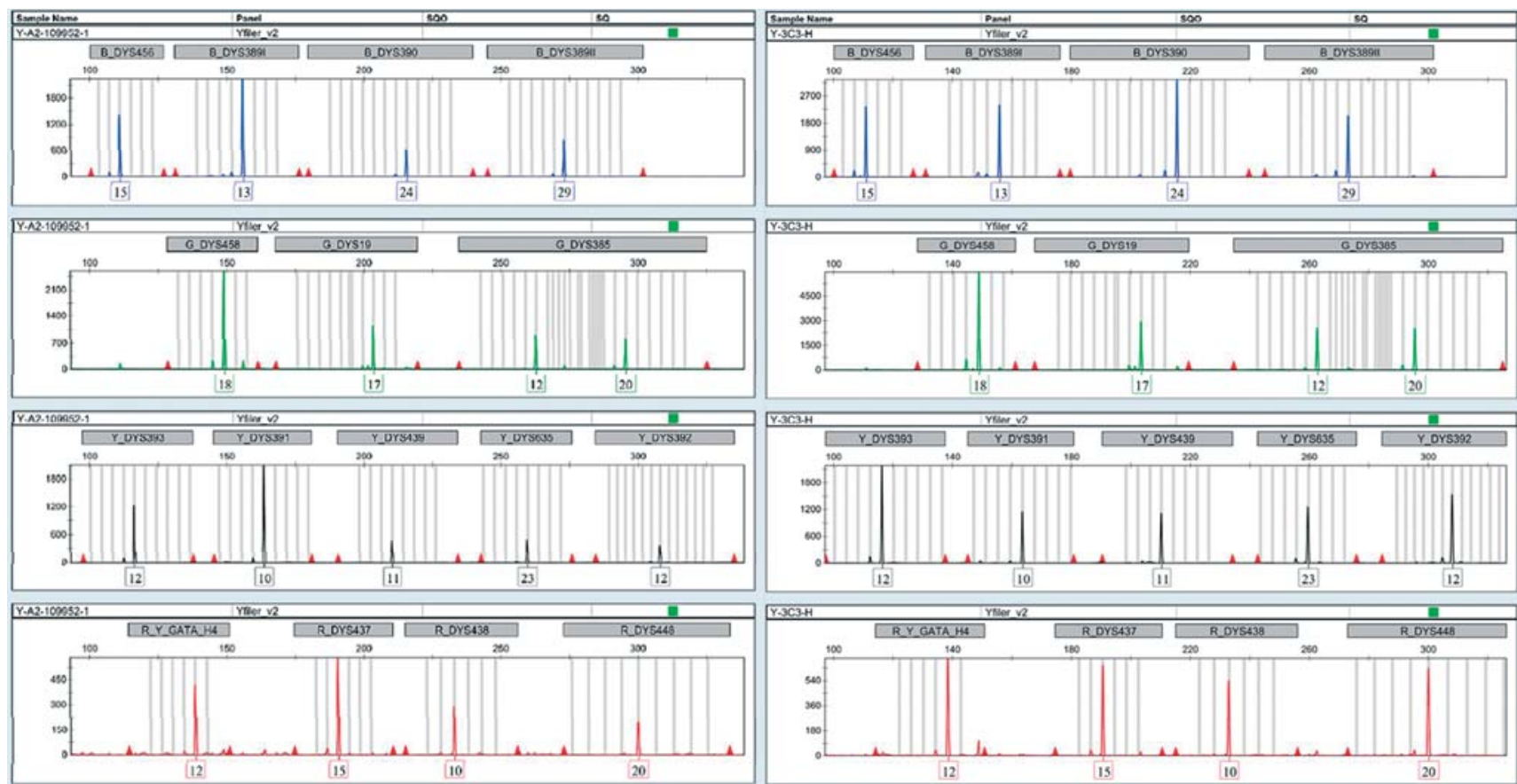

Fig. 4 Microsatellite analysis of $\mathrm{Y}$ chromosome loci of the jejunal tumor (left) showed identical polymorphic alleles to those of the paternal $\mathrm{Y}$ chromosome (right).

\section{References}

1 Yokoi K, Tanaka N, Furukawa K et al. Male choriocarcinoma with metastasis to the jejunum: a case report and review of the literature. J Nippon Med Sch 2008; 75: $115-117$

2 Iyomasa S, Senda $Y$, Mizuno K et al. Primary choriocarcinoma of the jejunum: report of a case. Surg Today 2003; 33: 948 -951

3 Chan GS, Ng WK, Chua DT et al. Raised serum hCG in a male patient caused by primary jejunal choriocarcinoma. J Clin Pathol 1998; 51: $413-415$
4 O'Neill CJ, Houghton F, Clarke J et al. Uterine gestational choriocarcinoma developing after a long latent period in a postmenopausal woman: the value of DNA polymorphism studies. Int J Surg Pathol 2008; 16: 226-229

5 Rodabaugh KJ, Bernstein MR, Goldstein DP et al. Natural history of postterm choriocarcinoma. J Reprod Med 1998; 43: 75-80

\section{Bibliography}

DOI http://dx.doi.org/ 10.1055/s-0032-1310018

Endoscopy 2012; 44: E360-E361

(c) Georg Thieme Verlag KG

Stuttgart · New York

ISSN 0013-726X

\section{Corresponding author}

L.-H. Wei, MD, PhD

Department of Oncology

National Taiwan University Hospital

7 Chung-Shan South Road

Taipei 100

Taiwan

Fax: +886-2-23711174

weilh1966@gmail.com 